\title{
Developing research capacity in the social sciences: a professionality based model
}

\author{
Dr Linda Evans \\ Reader in Education \\ School of Education \\ University of Leeds \\ Leeds, LS2 9JT \\ UK \\ E:mail: Linda.Evans@education.leeds.ac.uk
}

\section{Introduction}

With so many layers of research leadership why isn't every university bulging at the seams with internationally-recognised, prolific, grant-winning researchers producing top class, leading edge work? The UK higher education sector is illustrative. At the time of writing, UK universities have recently received the results of the research assessment exercise (RAE): the most important indicator of the quality of UK university research. Undertaken every few years (the previous RAE was in 2001), the process (which is expected to change in format and focus for the next exercise, occurring in 2012 , and which is to be known as the research excellence framework (REF)) involves universities submitting examples of the output of those of its academic staff deemed to have produced sufficient 'submissable' research. Submissions are then independently awarded grades that range from the highest four stars to one star, or even, in some cases, unclassified status. RAE 2008 found 17\% of submitted research activity, in aggregate, across the exercise as a whole, to be of world-leading $\left(4^{*}\right)$ quality, while $37 \%$ was judged to be internationally excellent in terms of originality, significance and rigour, but which nonetheless falls short of the highest standards of excellence $\left(3^{*}\right)$ (source: RAE 01/2008). Without wishing to put a dampener on the image of a healthy - indeed, an impressive - national research profile flagged up in the national media, I feel it is nevertheless important not to lose sight of the fact that $46 \%$ of submitted research activity failed to exceed $2^{*}$ status.

My own (UK) university's organisational structure, in incorporating designated research leadership roles at institutional (pro-vice chancellor), faculty (pro-dean), departmental (director of research) and research group (group co-ordinator and deputy co-ordinator) levels, is quite typical of research-intensive or research-focused universities worldwide. Yet still disparity persists in relation to research activity and output, both in terms of quantity and quality; a disparity that may be construed as indicating that some, or even much, research leadership is failing to achieve its purpose (though I fully appreciate that such an observation is greatly over-simplified and that - whilst space restrictions preclude my examining them here - many factors, in addition to research leadership, determine quality and quantity of activity and output). Precisely what this purpose is, of course, and the nature of the specific roles and responsibilities that are determined by that purpose, are identified by each university. For the sake of argument I shall nevertheless assume a general purpose of institutional research leadership (at any level: 
faculty, departmental, group, etc.) as the development of the institution's (or one of its departments') research capacity, adopting Mclntyre and Mclntyre's (1999, para. 1.4) definition: 'Research capacity is conceived as the most and best research which could be done now if there were the political will and the necessary resources for it to be done'. I define a research leader, in the context of this paper, as someone with designated authority and/or responsibility within her/his institution for developing the research capacity of others. I accept that this is a broad definition that must incorporate consideration of much variation in institutional nature, ambition and resources as well as in individual research leaders' orientation and capability, but to contextualise my interpretation of a research leader would necessarily narrow the applicability of my argument and the model that is its focus. I am reluctant to do so; rather, I present my model, below, as a theoretically-derived model that may be taken and adapted to fit different contexts and contextuallydetermined categories of research leadership.

My focus is on two inter-related components of developing institutional research capacity in the social sciences: developing a research culture (of a specific nature), and developing researchers. I use the term 'researcher' in the context of this paper to refer both to academics for whom research is, or is intended to be, a component of their work and of their contractual responsibilities, and to those employed in research only roles. First, however, I address the issue of the need for development, outlining the shortcomings of social science research and, by extension and implication, of the research leadership that I suggest is failing - at least in part - to achieve its purpose of developing institutional research capacity.

\section{The Shortcomings}

I emphasise at the outset that I do not imply that diversity in relation to the quality of research activity and output is peculiar to social science research. My narrow focus on one discipline simply reflects my concern that, as an 'outsider', I am unqualified to evaluate research in other disciplines in the same way that I may evaluate the discipline within which my own work and experiences are located. It is with the benefit of this 'insider' perspective that I suggest that many perceived shortcomings in social science research evidently represent lack of rigour and, more specifically, of theory generation. Valsiner (2001), for example, promoting the journal that he edits, derides the culture of nontheoreticism perceived to be prevalent within his research community: 'Culture \& Psychology is not another journal for publishing merely empirical papers ... It is a journal where the contributors are expected to make explicit their underlying theory of the systemic functioning of culture in psychological phenomena' (p. 10, original emphasis). He continues: 'In sum, Culture \& Psychology encourages rigorous work at the intersection of the theoretical and empirical realms of psychology. Such rigor could be glimpsed in psychology in the past, but has become displaced over recent decades by the social proliferation of the "empire of chance".' (Valsiner, 2001, p. 10)

Similar (though, in some cases, less pungent) criticisms have been levelled at other subject research communities, including education (e.g. Bridges, 1998, p. 85; Gorard, 2004, 2009; Gray, 1998, p. 23; Griffiths, 1998; 
Hammersley, 2009; Mclntyre and Mclntyre 1999; Ranson, 1998) and sociology (Freidson, 1994), as well as social science research in general (Gorard, 2004; LeCompte and Preissle, 1993). Moreover, a specific component of rigour: conceptual clarity, as I have suggested elsewhere (Evans, 2002), appears to be a neglected feature of much current social science research, creating deficiencies that others have identified in relation to their own areas of study (Donnelly, 2000; Freidson, 1994; Mumford, 1972; Nias, 1989; Thomas, 1997; Toomela, 2003, p. 35). The essential problem is summed up by the UK's Economic and Social Research Council (ESRC):

(T)here is concern that social science research in the UK, however conceptually sophisticated, can lack methodological rigour...there is also concern that there is an acute shortage of advanced methodological skills among the new generation of social scientists. (ESRC, 2001, p. 1)

The key issue, I believe, is more fundamental than the apparently very real problem of skills inadequacy (manifested by lack of rigour and theorygeneration) amongst social science researchers - which, incidentally, I do not consider to be confined to the 'new generation' of social scientists, but to be evident, too, amongst the 'old guard', and which, I have no doubt, is certainly not confined to the UK. The basis of the shortcomings evident within social science research is the lack of a culture of developmentalism amongst the researcher community.

\section{Social Science Research: a non-developmentalist culture}

Developmentalism, as I interpret it, is a commitment to (self)development: in the context of this paper, professional development in relation to researchers. I define professional development concisely as: the process whereby people's professionalism, or professionality, or professional practice may be considered to be enhanced, with a degree of permanence that exceeds transitoriness, which - though it may be revised in the future remains, for now, an adequate definition for applying to the argument below. (Aware that 'professionality' is not a widely-recognised term, I explain and expand upon it below.) A non-developmentalist culture, then, is one that fails generally to value developmentalism; a culture in which developmentalism is not generally and pervasively recognized as a pre-eminent attitude and/or activity.

I contend that the fundamental shortcoming of social science research is its lack of a pervasive, dominant culture of developmentalism; a lack of concern to develop professionally. Clearly there are social science researchers who do strive throughout their careers to increase their skills and competence; yet I believe there are many more who do not. From my own experience of having worked for almost twenty years as a member of one particular 'arm' of the social sciences research community: the educational research community; of having interacted with other researchers, and having read countless research papers, I suggest that a large proportion of 
researchers manifest the assumption that, rather like riding a bicycle, research skills, once mastered, require no refinement. Earning a doctorate - or if not that then one's first research project - is often considered and accepted as a professional developmental rite of passage that equips one sufficiently well for the entirety of a research or research-focused career: a research expertiserelated qualification that retains its validity throughout a working life span. What appears generally to be missing from the consciousness of many researchers is a commitment to - or perhaps, in many cases, simply an awareness of the necessity of - developing continually as a researcher. Such is the attitude to research development identified by Åkerlind (2007), as one of 'four different ways of thinking about development as an academic researcher':

Development continues until a threshold point of
competence and confidence ... or success and
recognition ... as a researcher has been achieved.
Then, once that stage is reached, the idea of
further development is not perceived as relevant.
After all, once one knows how to research
successfully, what else is there to learn? (p. 10)

It is very difficult to substantiate my suggestion that this is a widely-held viewpoint, since evidence of its being so is elusive. People are unlikely to identify themselves as being unconcerned or complacent about their professional development, either because they are unaware of or because they do not wish to admit to being so, and I have no reliable research-based evidence to support my impressions; (Åkerlind (2007) does not indicate the proportion of her sample who reflected this relatively non-developmentalist attitude, although her sample size is, in any case, too small to yield significant findings in this respect). Yet whilst I recognise fully the irony of drawing - out of necessity - upon impressionistic and experientially-acquired evidence that dilutes considerably the rigour of the basis of the point that I make that too many researchers lack a rigorous and developmentalist approach to their work, in my defence I argue that, as the references presented above demonstrate, I am evidently not alone in holding this contention. It is from evaluations of the quality of research in the field, as judged by its output, that I draw my anecdotal evidence, supported by similarly impressionistic and anecdotal evidence that appears across the social sciences.

\section{Developmentalism: a professionality-related interpretation}

'Professionality' is a term introduced by Hoyle (1975), who used it to identify two distinct aspects of teachers' professional lives: professionalism and professionality. Though he does not provide a stipulative definition of professionality, in 1975 Hoyle explained the distinction as being between status-related elements of teachers' work, which he categorised as professionalism, and those elements of the job that constitute the knowledge, skills and procedures that teachers use in their work, and which he categorised as professionality. After extensive consideration and analysis, I have defined professionality as: an ideologically-, attitudinally-, intellectually-, and epistemologically-based stance on the part of an individual, in relation to 
the practice of the profession to which s/he belongs, and which influences her/his professional practice (Evans, 2002, pp. 6-7).

In the 1970s Hoyle formulated two models of teacher professionality: 'For the sake of discussion we can hypothesize two models of professionality: restricted and extended' (Hoyle, 1975, p. 318). The characteristics used to illustrate these two hypothetical models created what may effectively be seen as a continuum with, at one end, a model of the 'restricted' professional, who is essentially reliant upon experience and intuition and is guided by a narrow, classroom-based perspective which values that which is related to the day-today practicalities of teaching. The characteristics of the model of 'extended' professionality, at the other end of the continuum, reflect: a much wider vision of what education involves, valuing of the theory underpinning pedagogy, and the adoption of a generally intellectual and rationally-based approach to the job. I use the term, professionality orientation to refer to individuals' location on an 'extended-restricted' professionality continuum. Professional development, then, since it incorporates (according to my definition of it) enhancement of individuals' professionality, involves progressing along the continuum from the 'restricted' to the 'extended' end, in order to enhance professional practice.

Yet every profession, I believe, has its own professionality continuum. There is a range of developmentalism within researching - the name I give to the profession' of doing research, to distinguish it from research as an activity and a product. It has its 'extended' and its 'restricted' professionals. There are, as Åkerlind (2007) implies, those who, as researchers, are considerably more developed than others.

'Restricted' researchers, as I interpret the term, parallel Hoyle's 'restricted' teachers in many respects. They may be very competent researchers whose knowledge of text book methodology is comprehensive. They may be effective at delivering what is generally considered high quality research. They may be reflective, analytical and meticulously thorough in the execution of their studies, and may yield findings that are informative and perhaps even transformational. Yet, for all this, they may still be 'restricted' professionals in relation to research because they apply their intellect to substantive, rather than methodological, development of their work. Indeed, Âkerlind's (2007, p. 10) findings support this: 'Academics who experience their research development in line with Categories $1-3^{\text {ii }}$ may be conducting research of a high quality, without necessarily experiencing the possibility of ongoing development as a researcher.'

Yet 'restricted' professionality also categorises researchers whose work has clearly identifiable qualitative limitations: researchers who are perhaps best described as 'competent' rather than 'scholarly'. This latter category of researchers may (though does not necessarily) include those who have published widely - even prolifically - and won research grants. Their work, in some cases, may be (though is not necessarily) based upon sound methodology and the findings that they report may be (though are not necessarily) both reliable and informative, yet they fall short of applying sufficiently deep analysis to these findings to generate contributions to theory, which I define as explanation that is universally-applicable of why and/or how things occur. This interpretation represents what I have called (Evans, 2002, p. 182) the 'elitist perspective' of theory. By this I mean perspectives that 
incorporate recognition of the status of theory as a much higher order form of propositional knowledge - and derived from a more rigorous intellectual process - than ideas, hypotheses, notions, hunches and structured reflection. I concur with Gorard's observation (2004, pp. 23-4): 'I realise that the word "theory" is used widely and loosely, and cannot hope to change that. I wish to distinguish the useful theory work from mere persiflage or worse'.

Of course, it is entirely inaccurate to present an image of the social science research profession as dichotomised between two extremes: 'restricted' and 'extended' professionality. Since it is a continuum that bridges them, rather than a boundary line that divides them, there are degrees of either category of professionality, and most researchers will lie somewhere between, rather than at one of, the two extremes. (Indeed, it is their locations along the full length of the continuum that accounts for the disparity of researcher quality to which I have referred.) I have used the extreme of 'restricted' professionality simply to illustrate the issue upon which this paper focuses. For the same purpose, and by the same token, I provide below an indication of what the 'extended' researcher might look like, and, in addition, to illustrate better the nature of the 'extended'-'restricted' professionality continuum as it relates to social science research, I follow Hoyle's (1975) example and present in Figure 1 a heuristic model of illustrative characteristics of researchers representing the two extremes of the continuum.

It is the examining of processes and questioning of the bases of established practice that characterises the 'extended' professional researcher. The 'extended' researcher is reflective and analytical, not just about the topic of her/his research, but about the research itself. S/he adopts a developmental approach to research, seeing her/himself as a professional who is constantly striving to improve her/his practice and who therefore is continually scrutinising it for inadequacies and weaknesses which may be reduced or removed. The 'extended' professional researcher seeks to increase and extend her/his research knowledge and skills further by keeping abreast of developments in methodology, or by contributing his/her own ideas for methodological development. At the very least, the 'extended' professional researcher is a career-long learner: someone who develops advanced research skills; at best, s/he is, in addition, a pioneer and innovator: a 'methodological scholar', who makes a significant contribution towards moving educational research forward. Such a person is what I refer to as an 'analytical researcher', but I emphasise that the word 'analytical' applies to the treatment of the research process itself, or to research-related issues, and is not confined to the treatment of research findings.

A culture of developmentalism implicitly or explicitly values what equates to 'extended' professionality. It is a culture wherein (self)development - that is, the enhancement of professionality, and through this, of professionalism and of practice - is recognised and valued as a pre-eminent activity. It is a culture wherein there is a shared commitment to progress steadily and continually along the professionality continuum, towards the 'extended' end. Since the fundamental shortcoming of social science research is, I argue, its lack of a pervasive, dominant culture of developmentalism, it is reasonable to suggest that the failure of much research leadership to fulfil its 
purpose of increasing institutional research capacity stems from its failure to develop adequately such a culture.

Figure 1: Characteristics illustrating the extremes of the 'restricted''extended' professionality continuum in relation to social science research

\begin{tabular}{|c|c|}
\hline $\begin{array}{l}\text { The researcher located at the } \\
\text { 'restricted' extreme of the } \\
\text { professionality continuum typically: }\end{array}$ & $\begin{array}{l}\text { The researcher located at the } \\
\text { 'extended' extreme of the } \\
\text { professionality continuum typically: }\end{array}$ \\
\hline conducts research that lacks rigour; & conducts highly rigorous research; \\
\hline draws upon basic research skills; & $\begin{array}{l}\text { draws upon basic and advanced research } \\
\text { skills; }\end{array}$ \\
\hline $\begin{array}{l}\text { fails to develop or extend her/his } \\
\text { methodological and analytical } \\
\text { competence; }\end{array}$ & $\begin{array}{l}\text { strives constantly to develop and extend } \\
\text { her/his methodological and analytical } \\
\text { competence; }\end{array}$ \\
\hline $\begin{array}{l}\text { utilises only established research } \\
\text { methods; }\end{array}$ & $\begin{array}{l}\text { adapts established research methods and } \\
\text { develops methodology; }\end{array}$ \\
\hline fails to develop basic research findings; & $\begin{array}{l}\text { generates and develops theory from } \\
\text { research findings; }\end{array}$ \\
\hline $\begin{array}{l}\text { perceives research methods as tools } \\
\text { and methodology as a task-directed, } \\
\text { utilitarian process; }\end{array}$ & $\begin{array}{l}\text { perceives research methodology as a field } \\
\text { of study in itself; }\end{array}$ \\
\hline $\begin{array}{l}\text { applies low level analysis to research } \\
\text { data; }\end{array}$ & $\begin{array}{l}\text { strives constantly to apply deep levels of } \\
\text { analysis to research data; }\end{array}$ \\
\hline $\begin{array}{l}\text { perceives individual research studies as } \\
\text { independent and free-standing; }\end{array}$ & $\begin{array}{l}\text { recognises the value of, and utilises, } \\
\text { comparative analysis, meta-analysis, } \\
\text { synthesis, replication, etc.; }\end{array}$ \\
\hline $\begin{array}{l}\text { perceives individual research studies as } \\
\text { finite and complete; }\end{array}$ & $\begin{array}{l}\text { constantly reflects upon, and frequently } \\
\text { revisits and refines, his/her own studies; }\end{array}$ \\
\hline $\begin{array}{l}\text { struggles to criticise literature and } \\
\text { others' research effectively; }\end{array}$ & $\begin{array}{l}\text { has developed the skill of effective } \\
\text { criticism and applies this to the formulation } \\
\text { of his/her own arguments; }\end{array}$ \\
\hline $\begin{array}{l}\text { publishes mainly in 'lower grade' } \\
\text { academic journals and in professional } \\
\text { journals/magazines; }\end{array}$ & $\begin{array}{l}\text { publishes frequently in 'high ranking' } \\
\text { academic journals; }\end{array}$ \\
\hline $\begin{array}{l}\text { is associated mainly with research } \\
\text { findings that fall into the 'tips for } \\
\text { practitioners' category of output. }\end{array}$ & $\begin{array}{l}\text { recognises research's value to policy and } \\
\text { practice, engages with practitioners and } \\
\text { policy-makers and disseminates her/his } \\
\text { findings in ways that are comprehensible } \\
\text { to them, whilst also disseminating ground- } \\
\text { breaking theoretical issues and } \\
\text { contributing to, and taking a lead in } \\
\text { developing, discourse on theory. }\end{array}$ \\
\hline
\end{tabular}

\section{FOSTERING CULTURES OF DEVELOPMENTALISM}

I have argued elsewhere (Evans, 2009) that the research profession's lack of a culture of developmentalism is evident through a general lack of 
engagement in continuing professional development (CPD), and through the apparent failure of researchers - particularly those who are experienced and established - to recognise the need for and the advantages of career-long CPD. Åkerlind's (2007, p.2) research provides some corroboration of this:

The finding that at least some senior academics show a more limited understanding of researcher growth and development indicates that early understandings of research development may not spontaneously shift with experience, but may become entrenched, limiting the potential development of a researcher throughout his/her career.

This paucity of CPD provision and take-up, I observe (Evans, 2009), contrasts sharply with CPD provision and engagement levels of many other professions (e.g. teaching, medicine, pharmacy, social work) that may consequently be categorised as developmentalist professions (though I qualify this observation with my suggestion that, for pragmatic reasons, such developmentalist professional cultures were, in fact, initially imposed from above, rather than fostered within the professions). I also make the very important point that what I call 'ostensible CPD' - that is, clearly observable, dedicated professional development events and opportunities - is by no means the only professional development channel, and that much development occurs 'implicitly', to use Michael Eraut's term (2004; 2007) and imperceptibly, through what has come to be known as situated learning. Its imperceptibility, which would by definition preclude its being recognised, even by the 'developee', may explain in part and, as a result, complicate, Âkerlind's (2007) finding, referred to above.

Notwithstanding the broader picture provided by the incorporation of these qualifications and clarifications, there is clearly a culture-building role for institutional research leaders at all levels. Fundamentally, it is research cultures of a certain kind that need to be built and sustained; specifically, research cultures of 'extended' professionality, which equate to cultures of developmentalism.

\section{Developing a research culture: issues and considerations}

We may surmise from their profiles and esteem indicators, such as RAE results, that some universities and/or their departments have evidently already enjoyed much success in developing and sustaining vibrant research cultures. In the UK these are most likely to (though may not necessarily) be pre-1992 universities" iii in Australia, the sandstone universities: the 'usual suspects'. Yet there is more to a research culture than an impressive list of research output and income, and a good RAE profile, and to equate such indicators automatically with research cultural vibrancy risks over-simplifying matters.

The risk is largely tied up with conceptual clarity, for what, precisely, is meant by a 'research culture' is not easy to convey; research cultures are variously interpreted and defined. My on-going review of a broad range of social studies literature has revealed a plethora of definitions of culture leaving aside the 'research' qualification. While Hofstede (2001) refers to 
culture as 'a collective programming of the mind', for example, Cole (2000) interprets it as a system of artefacts (its fundamental constituents). Moreover, some of the work focusing on research in $\mathrm{HE}$, without necessarily labelling it as such, incorporates reference to and examination of what may, according to some conceptions, be categorised as research culture (e.g. Fox and Mohapatra's (2007, p. 545) reference to 'work climate', and Louis et al's (2007, p. 315) equation of 'organizational climate' and 'work-group climate' with 'a shared culture that is focused on research').

Deem and Brehony (2000) ask (p. 158): 'What does it mean to speak of academic research cultures?' Their suggestion is that 'academic research cultures include disciplinary or interdisciplinary ideas and values, particular kinds of expert knowledge and knowledge production, cultural practices and narratives (for instance how research is done, and how peer review is exercised), departmental sociability, other internal and external intellectual networks and learned societies.' The point of consensus amongst a range of definitions and interpretations of either university or academic culture (e.g. Clark, 1983; Schein, 1996) is the focus on shared thinking, ideas, understanding and/or behaviour. Here, in order to proceed with the discussion that is the focus of this paper, I present a working explanation of an institutional research culture as: shared values, assumptions, beliefs, rituals and other forms of behaviour whose central focus is the acceptance and recognition of research practice and output as valued, worthwhile and preeminent activity. Developing such a culture is not simple, straightforward or formulaic. If it were, every university would be applying the winning formula.

The role of research (or, indeed, any other category of) leaders in promoting, building and sustaining research cultures is not without contention, not least because the processes involved in doing so are far from clear, being clouded by social theory's unresolved issue of structure and agency: do individuals shape and define cultures, or are they shaped and defined by them? (Archer, 1988). Yet in one sense the difficulty in shaping and building research cultures lies in their relatively vague and poorly defined shape: what, precisely, does a research culture look like? If it is not palpable, then is it at least discernible - to 'outsiders' as well as 'insiders' - and, if so, in a subtle, understated way, or in an unmistakeably obvious way that borders on ostentation? What sort of things ought people to be doing if, as its 'participants' or 'constituent parts' (depending on the extent of their agential roles, and how these are interpreted), they are collectively creating a research culture? In what direction should they be going? What are their foci; what are their purposes? Certainly, research activity is the fundamental purpose, but what form(s) should this activity take, with what levels of intensity should it be carried out, measurable against what standards, and with what outcomes, in order for what is created or formed to be categorised as a research culture? And to what extent are the answers to these - and other pertinent - questions dependent upon the institution, and relative to its status, purposes, and resources? May a research culture in a 'big fish' ivy league, sandstone, or Russell Group ${ }^{\text {iv }}$ university or department be quite a different animal from one in a 'minnow' institution? The key point is that designated institutional research leadership often lacks the clarity and specificity of direction in which to point people: the clarity and direction that address the sorts of questions listed above. 
If, on the other hand, the intention is to create a more specific culture of 'extended' research professionality, the direction is much better signposted and the way ahead much clearer.

\section{Developing a culture of 'extended' professionality: issues and considerations}

Elsewhere I present both the rationale for, and a description of, a culture of 'extended' professionality (Evans, 2002; 2007), which, essentially, is a culture of developmentalism, manifested by commitment to individuals' career-long professional development as researchers. It is based upon a developmental framework that involves progression from 'restricted' to 'extended' researcher professionality.

Developing such a culture of developmentalism, however, involves fostering a commitment to progression along a development continuum such as that implied by the models of 'extended' and 'restricted' professionality presented in figure 1. Here the focus shifts from the 'plurality' of a culture to the 'singularity' of the professional development of individuals. Understanding the professional development process in individuals is key to creating a developmentalist culture.

Developing researchers into 'extended' professionals: the role of leadership

No matter where, precisely, it occurs in the process, recognition of what are perceived as inadequacies or imperfections - no matter how slight - in one's current work situation or practice is essential to professional development (Evans, 2008). Dissatisfaction often prompts the quest for improvement, while unplanned improvement, or unsolicited recognition of a potential 'better way' of doing things, lead to retrospectively recognised dissatisfaction. Satisfaction, on the other hand, fosters complacency. Only by recognising the inadequacies in their current practice will researchers appreciate the need to improve: that is, to progress along the 'restricted''extended' professionality continuum. Herein lies a distinct role for research leaders.

There is much agreement that the most successful form of researcher professional development is situated: learning that takes place in context (Pollard, 2007; Raddon, 2006; Rees et al, 2007), through communities of practice (Wenger, 1998), rather than through a 'technical model' that is focused on skills and competences delivered through formal provision such as courses and workshops. Certainly such a situated learning approach is compatible with the development of a culture of 'extended' professionality. More specifically, individuals' recognition of their own location or position on the 'restricted'-'extended' professionality continuum - and of the direction they need to take in order to progress - is likely to be made much easier within a context where comparisons may be made with others, particularly others who have manifestly progressed further along the continuum. (Using the 'restricted'-'extended' professionality continuum in my own teaching to practising professionals, I find that the models invariably ring true to these students, and that they are both willing and able to locate themselves on the continuum in relation to current and former colleagues whom they consider to 
be more and less 'extended' than they themselves.) If designated researcher leaders do not, themselves, represent such yardsticks against which to measure good practice because they do not form part of the close circle of contacts within which are situated those whose professionality needs to be enhanced, then their responsibilities must surely include ensuring that such role models are placed within the sphere(s) of every potential 'developee'. Moreover, through both 'restricted' and 'extended' professionality models, research leaders may communicate their visions of the research cultures they are committed to building. They may do this by making the characteristics of 'extended' professionality specific to their own contexts, institutional needs, and purposes, and by promoting this model as an example of good practice, encouraging others to work towards developing the researcher characteristics that it incorporates. Similarly, research leaders may write their own models of 'restricted' professionality, based upon those characteristics and pervasive practice that they see within their own institutions, but which they wish to reduce or eradicate. By labelling such practice and attitudes as manifestations of 'restricted' professionality, and presenting the model as a professional stance and position to advance and move away from, they may encourage others to be introspective in analysing the shortcomings of their practice, and to develop a commitment to moving forward. Thus, models of 'restricted' and 'extended' professionality, re-written and contextualised by research leaders, may serve as the articulation of their visions for developing research capacity and output. These visions are essential for providing the clarity and specificity that are often missing in attempts to promote and build research cultures that are not framed within a specific model.

\section{A developmentalist culture of 'extended' professionality: addressing the shortcomings of social science research}

A culture of 'extended' researcher professionality involves a commitment to development - continued, career-long development - on the part of everyone, research leaders included. For, like the mythical end of the rainbow, the elusive 'extended' extreme of the continuum may never actually be reached; it will perpetually remain just out of reach to even the most 'extended' of professionals. This should not serve as a deterrent; rather, it should provide the stimulus for the recognition of those aspects of our current practice that may be improved, even if only slightly: the search for a 'better way' that, I suggest, is a key component of the professional development process in individuals. Awareness of the possibility of there being a 'better way' reflects the kind of healthy developmentalist attitude that characterises 'extended' professionality. 'Restricted' professionality is characterised either by ignorance of the standards of quality expected and achievable, or by the complacency and arrogance that underpins the conviction that there is nothing more to learn.

Of particular importance, though, are the clarity and specificity of purpose and direction provided by the development of a culture that is based upon a model of 'extended' professionality. These lie in the illustrative typical characteristics that provide an explicit yardstick of researcher professionality that individuals may adopt as a framework for their own development, and 
against which they may measure their progress. Such clarity and specificity potentially provide much support to the research leadership role. I believe that one of the many reasons why there is such an evident diversity of quality within social science research is that clear quality guidelines and yardsticks have seldom been provided. This omission needs to be addressed.

It would be helpful if the research communities of each of the recognised social science subject fields were to agree upon and formulate their own explicit quality yardsticks or criteria and aspirational markers. This would potentially create an evenness - a level playing field - that would be accepted as fair and manageable. Yet even if this does not occur, then at the very least individual universities and faculties or subject departments within universities that are seriously committed to raising and sustaining the quality of their research should formulate their own standards of excellence to guide their researchers and to make institutional and/or departmental expectations and aspirations crystal clear. As I imply above, these need not, of course, necessarily be the typical 'extended' professionality characteristics presented in my model (figure 1). The research leader's skill lies, in part, in formulating a model that is not only specific and relevant to the context in which the targeted 'developees' are located, but is also motivating without presenting what are perceived as unachievable high levels of expected attainment. Moreover, not only should any illustrative typical 'extended' professional characteristics correlate with and reflect the institution's or department's own aims, objectives and circumstances (including resources), but they should also go beyond my model by providing unambiguous clarity and specificity: what, for example, is meant by the 'highly rigorous research', 'advanced research skills', 'effective criticism' or 'deep levels of analysis' that I include in my list of typical 'extended' professionality characteristics is, of course, entirely subjective.

Herein lies part of the problem: many researchers may genuinely consider their analyses already to be 'deep', while others who hold higher standards may dismiss them as superficial and, as a result, woefully inadequate. Such mismatch of both standards and constructs needs to be addressed; institutional research leaders must decide whether they wish to apply contextually-defined conceptions of quality or frame their professional development endeavours against a more relatively-defined quality that goes beyond institutional or departmental contextual considerations and priorities.

Above all, research leaders need to lay their cards on the table: they need to be explicit and 'up-front' about precisely what skills, attitudes, knowledge and understanding - and, stemming from these, what specific kinds and quality of output - they want to promote and develop. What this amounts to is developing the clear vision to which I have referred, communicating it to those for whose development they are responsible, and encouraging them to share this vision and 'buy into' it. Where disparity in research activity and quality occurs, such a vision is either failing to be communicated effectively, or, for any of several possible reasons, it is failing to be taken on board - to be 'bought into' - consistently, seriously, and evenly.

A model of 'extended' researcher professionality at the heart of a research leader's vision has the potential to bring the vision to life, and to inject into it a clarity of focus that is motivational and directional. For the point about building a professional development programme around a continuum- 
based model is that it has the capacity to accommodate individuals' different developmental needs. Everyone will be located somewhere along the continuum, and by whatever processes are chosen - whether they be ostensible CPD opportunities that fit in with the technical model of professional development, or more ad hoc and opportunistic situated 'implicit' learning - everyone has the potential and the capacity to progress along it, towards the 'extended' end, however that may be defined. This is unlikely to eradicate entirely the disparity of research quality that I began by addressing, for differentiation accommodates diversity. What it has the capacity to do, however, is to reduce considerably the complacency, arrogance and ignorance that are the hallmarks of 'restricted' professionality and of the culture of non-developmentalism that undermines the quality of social science research(ing).

\section{REFERENCES}

Åkerlind, G. (2007). Academic research development: growing as a researcher. Proceedings of the 30th HERDSA Annual Conference [CD-ROM], Adelaide, 8-11 July.

Archer, M. S. (1988). Culture and agency: the place of culture in social theory. Cambridge, England: Cambridge University Press.

Bridges, D. (1998). Research, dissent and the reinstatement of theory. In J. Rudduck and D. McIntyre (Eds.), Challenges for educational research (pp. 8286). London: Paul Chapman.

Clark, B.R. (1983). The higher education system: academic organization in cross-national perspective. Berkeley, CA: University of California Press.

Cole, M. (2000). Cultural psychology: a once and future discipline. Cambridge, Mass., USA: Harvard University Press.

Deem, R. and Brehony, K. (2000). Doctoral students' access to research cultures - are some more unequal than others? Studies in Higher Education, 25 (2), 149-165.

Donnelly, C. (2000). In pursuit of school ethos. British Journal of Educational Studies, 48 (2), 134-154.

Eraut, M. (2004). Informal learning in the workplace. Studies in Continuing Education, 26 (2), 247-273.

Eraut, (2007). Learning from other people in the workplace. Oxford Review of Education, 33 (4), 403-422. 
Economic and Social Research Council (ESRC) (2001). Information on research methods programme: introduction and summary. Swindon, England: ESRC.

Evans, L. (2002). Reflective practice in educational research: developing advanced skills. London: Continuum.

Evans, L. (2007). Researcher development in the social sciences: an 'extended'-restricted' professionality-based model. Paper presented within the symposium, Perspectives on academics' development as researchers, at the Annual Conference of the Society for Research into Higher Education (SRHE), Brighton, England.

Evans, L. (2008). What is teacher development and how is it achieved? Ontological and processual models. Paper presented within the symposium, Issues in European teacher development: linking theory and practice, at the European Conference on Educational Research, University of Gothenburg, September $12^{\text {th }}$. Retrieved January $30^{\text {th }}, 2009$, from http://www.leeds.ac.uk/educol/documents/175518.pdf

Evans, L. (2008c). Is educational research(ing) a profession? Examining issues of professional status and developmentalism. Paper presented at the Annual Conference of the SRHE, Liverpool, England.

Evans, L. (2009). S/he who pays the piper calls the tune? Professionalism, developmentalism and the paucity of in-service education within the research profession, Professional Development in Education, 35 (2), 289-304.

Fox, M. F. and Mohapatra, S. (2007). Social-organizational characteristics of work and publication productivity among academic scientists in doctoralgranting Departments. Journal of Higher Education, 78 (5), 542-571.

Freidson, E. (1994). Professionalism reborn: theory, prophecy and policy. Cambridge, England: Polity Press, in association with Blackwell Publishers.

Gorard, S. (2004). Three abuses of 'theory': an engagement with Roy Nash. Journal of Educational Enquiry, 5 (20), 19-29.

Gorard, S. (2009). All evidence is equal. Paper presented at the seminar, Judging Quality in Qualitative Research, University of Leeds Institute of Lifelong Learning, $27^{\text {th }}$ January.

Gray, J. (1998). An episode in the development of educational research. In J. Rudduck and D. Mclntyre (Eds.) Challenges for Educational Research (pp. 17-46). London: Paul Chapman.

Griffiths, M. (1998). Educational research for social justice. Buckingham, England: Open University Press. 
Hammersley, M. (2009). The problem of assessing qualitative research: neither proceduralism nor decisionism, just epistemic judgement. Paper presented at the seminar, Judging Quality in Qualitative Research, University of Leeds Institute of Lifelong Learning, $27^{\text {th }}$ January.

Hofstede, G. (2001). Culture's consequences: comparing values, behaviors, institutions, and organizations across nations. Thousand Oaks, CA., USA: Sage

Hoyle, E. (1975). Professionality, professionalism and control in teaching. In V. Houghton et al. (Eds.), Management in education: the management of organisations and individuals. London: Ward Lock Educational in association with Open University Press.

LeCompte, M. D. and Preissle, J. (1993). Ethnography and qualitative design in educational research. San Diego, CA., USA: Academic Press.

Louis, K. S., Holdsworth, J. M. and Campbell, E.G. (2007). Becoming a scientist: the effects of work-group size and organizational climate. Journal of Higher Education, 78 (3), 311-336.

Mclntyre, D. and McIntyre, A. (1999). ESRC Teaching and Learning Programme: Capacity for Research into teaching and Learning - Final Report.

Mumford, E. (1972). Job Satisfaction: a study of computer specialists. London: Longman.

Nias, J. (1989). Primary teachers talking: a study of teaching as work. London: Routledge.

Pollard, A. (2006). So, how then to approach research capacity building? Research Intelligence, Issue 97, 18-20.

Raddon, A. (2006). Drawing the boundaries in academic work: individual views and experiences of teaching, research and administration. Paper presented at the Annual Conference of the SRHE, Brighton, England.

RAE 01/2008. Research Assessment Exercise 2008: the outcome (December 2008). a joint publication of the Higher Education Funding Council for England (HEFCE), Scottish Funding Council, Higher Education Funding Council for Wales (HEFCW) and the Department for Employment and Learning.

Ranson, S. (1998). The future of educational research: learning at the centre. in J. Rudduck and D. Mclntyre (Eds.), Challenges for Educational Research (pp. 47-66). London: Paul Chapman.

Rees, G., Baron, S., Boyask, R. and Taylor, C. (2007). Research-capacity building: professional learning and the social practices of educational research. British Journal of Educational Research, 33 (5), 761-779. 
Schein, E.H. (1996). Culture: the missing conception in organization studies, Administrative Science Quarterly, 41, 229-240.

Thomas, G. (1997). What's the use of theory? Harvard Educational Review, 67 (1), 75-104.

Toomela, A. (2003). Culture in psychology: current controversies. Culture and Psychology, 9(1), 35-45.

Valsiner, J. (2001). The first six years: culture's adventures in psychology. Culture \& Psychology, 7 (1), 5-48.

Wenger, E. (1998). Communities of practice. Cambridge, England: Cambridge University Press.

\footnotetext{
${ }^{\mathrm{i}}$ In my detailed examination (Evans, 2008c) of the professional status of educational research I present arguments for and against its being a profession. Here, since it is peripheral to this discussion, I simply represent research as a profession, for the sake of advancing the paper's main argument.

ii Åkerlind's four categories refer to: 1.becoming confident as a researcher; 2 . becoming recognised as a researcher; 3 . becoming more productive as a researcher; and 4. becoming more sophisticated as a researcher.

iii 1992 marked the end of the binary divide that separated polytechnics from universities. Thereafter polytechnics were given university status and are often still referred to as 'new' or, alternatively, 'modern' universities.

${ }^{\text {iv }}$ An association, led by Leeds University's vice chancellor, Professor Michael Arthur, of 20 major research-intensive universities of the UK (http://www.russellgroup.ac.uk)
} 